\title{
Preliminary report: one of the PD-1 gene variants may be a valuable marker for colorectal cancer
}

Yosra Lamami ${ }^{1,2}$, Roya Mesediyeva ${ }^{3}$, Soykan Arıkan ${ }^{4}$, Şeyda Ercan³, Hilal Fındık Kıyann ${ }^{3}$, Cihat Tatar Ali Emre Nayci ${ }^{4}$, Ammad Farooqi', ilhan Yaylim³ ${ }^{3}$, Bayram Kıran ${ }^{1}$

\begin{abstract}
${ }^{1}$ Genetic and Bioengineering Department, Institute of Science, Faculty of Science, Kastamonu University, Kastamonu, Turkey

${ }^{2}$ Cell Biology Research Group, Human Tissue Culture Department, Biotechnology Research Centre, Tripoli, Libya

${ }^{3}$ Molecular Medicine Department, Aziz Sancar Institute of Experimental Medicine, Istanbul University, Istanbul, Turkey

${ }^{4}$ General Surgery Clinics, Istanbul Training and Research Hospital, Istanbul, Turkey ${ }^{5}$ Laboratory for Translational Oncology and Personalized Medicine, Rashid Latif Medical College, Lahore, Pakistan
\end{abstract}

Submitted: 13 December 2017

Accepted: 24 March 2018

Arch Med Sci Civil Dis 2018; 3: e34-e40

DOI: https://doi.org/10.5114/amscd.2018.75533

Copyright $\odot 2018$ Termedia \& Banach

\begin{abstract}
Introduction: Programmed death-1 (PD-1) is an immunosuppressive molecule, which has importance for tumor-cell-mediated immune escape. We investigated the role of PD-1.5 C/T gene polymorphisms in the susceptibility and progression of colorectal cancer (CRC).

Material and methods: In this study, the $P D-1.5 \mathrm{C} / T$ polymorphism was investigated in 99 CRC patients and 150 healthy controls by the nested polymerase chain reaction-restriction fragment length polymorphism method.

Results: The distributions of PD-1.5 C/T genotypes and alleles were in agreement with Hardy-Weinberg equilibrium in controls $(p>0.05)$ but not in CRC patients $(p=0.02)$. We found a statistically significant difference between CRC patients and controls for the genotypic distribution of PD-1.5 C/T genotypes $(p=0.003)$ and also for alleles $(p=0.004)$. The T allele frequency was higher in patients than controls $(p=0.001)$. The patients who had a $C$ allele with distance metastasis had higher frequency of heterozygous $C T$ genotype of $P D-1.5 \mathrm{C} / \mathrm{T}$ polymorphism than those with no metastasis $(p<0.001)$. We also detected higher frequency of CC genotype in patients who had angiolymphatic invasion $(p=0.043)$. The patients who had a mucinous component had higher frequency of the $T$ allele than those with absence of the mucinous component $(p=0.023)$.

Conclusions: Our results showed significant associations between PD-1 genotypes and CRC susceptibility and progression of the disease.
\end{abstract}

Key words: PD-1.5 C/T, polymorphism, colorectal cancer.

\section{Introduction}

Colorectal cancer (CRC) is one of the most common cancers among people worldwide, following lung and breast cancers with almost 1.4 million new cases in 2012 [1]. One in 22 men and one in 24 women will be diagnosed with CRC in their lifetime. An estimated 27,150 men and 23,110 women will die from CRC in 2017 [2].

\author{
Corresponding authors: \\ Ilhan Yaylim \\ I.U.DETAE Aziz \\ Sancar Institute of \\ Experimental Medicine \\ Istanbul University \\ Vakif Gureba Cad \\ 34280 Istanbul, Turkey \\ Phone: +9005324125478 \\ E-mail: \\ ilhanyaylim@gmail.com \\ Bayram Kıran \\ Genetic and \\ Bioengineering \\ Department Institute \\ of Science Faculty of Science \\ Kastamonu University \\ 37200 Kastamonu, Turkey \\ Phone: +90 05327811170 \\ E-mail: \\ baykiran@hotmail.com
}


Patient survival is extremely dependent on the tumor stage at the time of diagnosis. At an early stage just $40 \%$ of CRC cases are diagnosed and nearly $50 \%$ of presently diagnosed patients will develop into metastatic cancer [3]. Metastatic CRC remains the fourth most common cause of death from the disease of cancer [4]. In spite of the recent progress in diagnosis and treatment, including the introduction of targeted therapies, the prognosis of these advanced CRC cases remains poor [5]. Improvement in molecular biology has helped clarify some of the genetic mechanisms related to colorectal carcinogenesis [3].

Maintaining the totality of genomic DNA is necessary for correct cell function. Genome disorders can predispose to the development of several malignancies, including CRC. The CRC can be initiated by DNA damage induced by chemical agents, smoking, alcohol consumption, and fat metabolism [6, 7].

Aggressive tumors have an ability to survive and proliferate in difficult environmental conditions [8]. Tumor release of factors supports the formation of angiogenesis and disrupts nearby tissue architecture, which encourages the invasion and metastatic spread. The role of the immune system are known to destroy cancer cells by helping innate effectors or some specific defensive cells or to allow for the presentation of tumor antigens to T cells [9]. Immune organization of aggressive cancerous growth is often raised by tumor expression of ligands that hamper effector immune responses throughout the stimulation of immune checkpoints.

One of such checkpoints is programmed death-1 (PD-1). Programmed death-1 is considered to have a central role in the tumor microenvironment where tumor-specific $T$ cells continue to keep their antitumor functions. Programmed death-1, expressed by activated T cells, is an inhibitory cell surface receptor involved in the regulation of $\mathrm{T}$ cell activity during immunity and tolerance [10].

The programmed death 1 (PD-1) gene is located on human chromosome 2 on a segment (2q33 q37) encoding a 50-55 KD a type I transmembranous glycoprotein [11], and containing many other regulatory genes, for instance CTLA-4 and CD28 [12-15]. The PD-1 receptor provides an inhibitory signal, and when it interacts with its two ligands PD-L1 and PD-L2, it can powerfully hamper both proliferation and cytokine production by $\mathrm{CD}^{+}$and $\mathrm{CD} 8^{+} \mathrm{T}$ lymphocyte glycoprotein $[16,17]$. Programmed death-1 has been suggested to be implicated in influencing the cancer cells' evasion of the host immune system after contact with its two ligands. Moreover, polymorphisms or modification in this gene can have an effect on its task. For instance, single nucleotide polymor- phism (SNP) is one of the most important factors affecting cancer susceptibility. In this regard, the latest studies have focused on the information that PD-1 polymorphisms are linked with susceptibility to many types of cancer, for instance, gastric cancer [18], gastric cardia adenocarcinoma [19], colon cancer [20], breast cancer [21, 22], esophageal cancer [23], hepatocellular carcinoma [24] and cervical cancer [25]. Immunohistochemical investigation has shown a connection between PD-1 expression and cancer, including CRC [26, 27]. However, the relation between PD-1 polymorphisms and CRC was not well known in various populations.

One of the important polymorphisms is PD$1.5 \mathrm{C} / \mathrm{T}$, situated in exon 5 (position 7785) [28]. There are different studies relevant to PD-1 polymorphism and autoimmune disease [28-30] but there is a small number of studies that show the association between PD-1.5 C/T polymorphism and cancer $[21,22,31]$. The fact is that the exact role of PD-1.5 C/T gene polymorphisms in cancer is still unexplainable. Therefore, this subject has come into the focus of researchers' interest to fully understand its effect on cancer and other diseases.

We aimed to analyze the distribution of genotypes and alleles resulting from polymorphism at position PD-1.5 C/T in CRC patients among the Turkish population, and compare them to those of healthy individuals. Moreover, the relations between this single nucleotide polymorphism and clinicopathological parameters of the patients were studied to wholly understand the role of PD$1.5 \mathrm{C} / \mathrm{T}$ gene polymorphisms in susceptibility to and progression of CRC.

\section{Material and methods}

\section{Participants}

The mean ages of patients and the control group were ( $62.06 \pm 12.8$ years) and $(54.50 \pm 16.47$ years) years, respectively. For the patient group, diagnosis and cancer status were confirmed by standardized questionnaire, pathological records and medical records obtained from Istanbul Education and Research Hospital (Samatya). The control subjects were randomly selected among healthy volunteers. The American Joint Committee on Cancer (AJCC) TNM classification was used to define the stage of CRC. Tumor staging was categorized as T1, T2, T3 and T4 related with localization of the tumor. The Ethics Committee of Istanbul Education and Research Hospital approved our study. The protocol of the study was compatible with the World Medical Association Declaration of Helsinki (Ethical Principles for Medical Research Involving Human Subjects). 


\section{DNA Isolation}

Genomic DNA was extracted from peripheral whole blood containing EDTA according to the salting-out technique. DNA was isolated from the blood leukocytes in $10 \mathrm{ml}$ of EDTA by the method of Miller et al. based on sodium dodecyl sulfate lysis, ammonium acetate extraction, and ethanol precipitation [32].

\section{SNP detection}

Genotyping was performed by the polymerase chain reaction (PCR) and RFLP. The PCR reactions were carried out using a "MyCycler Thermal Cycler" from Bio-Rad. For PCR amplification, the primers for $\mathrm{PD}-1.5 \mathrm{C} / \mathrm{T}$ polymorphism were: forward 5'-GGACAGCTCAGGTAAGCAG-3' and reverse 5'-AAGAGCAGTGTCCATCCTCAG-3'. For detection of the PD-1.5 C/T RFLP, 20 ng genomic DNA was amplified with $2.5 \mu \mathrm{l} 10 \times \mathrm{PCR}$ buffer, $1 \mu \mathrm{l}$ of $3 \mathrm{mM} \mathrm{MgCl}_{2}, 1 \mu \mathrm{l}$ of $0.2 \mathrm{mM}$ dNTP, $0.5 \mu \mathrm{l}$ of 0.2 $\mathrm{mM}$ of each primer and $0.2 \mu \mathrm{l}$ of Taq polymerase (Fermentas, Lithuania) in a $25 \mu \mathrm{l}$ reaction volume. The PCR conditions for PD-1.5 C/T were initially a melting step of $5 \mathrm{~min}$ at $95^{\circ} \mathrm{C}$, then 35 cycles of $45 \mathrm{~s}$ at $94^{\circ} \mathrm{C}, 45 \mathrm{~s}$ at $57^{\circ} \mathrm{C}$ and $45 \mathrm{~s}$ at $72^{\circ} \mathrm{C}$, and finally an elongation step of $5 \mathrm{~min}$ at $72^{\circ} \mathrm{C}$ The PCR products (213 bp) were digested with Pvull (Invitrogen; Thermo Fisher Scientific, Waltham, MA, USA) restriction enzyme $\left(37^{\circ} \mathrm{C}\right.$ for $\left.1 \mathrm{~h}\right)$ and electrophoresized on $3 \%$ agarose gels and stained with ethidium bromide. Genotypes were determined as CC (213 bp), CT (213,157,56 bp), TT (157,56 bp) for PD-1.5 C/T polymorphism.

\section{Statistical analysis}

Statistical analysis was performed using the SPSS software package (revision 21.0; SPSS Inc., Armonk, NY, USA). Descriptive statics include the mean, standard deviation, and percentages. Mean values of differences in clinical parameters between patients and controls were compared with unpaired Student's $t$-test and expressed as the mean \pm SD. The Hardy-Weinberg equilibrium was tested for all polymorphisms. Allele frequencies were estimated by gene counting methods. For comparing the distributions and differences of genotypes and alleles between patients and controls, the $\chi^{2}$ test was used. Values of $p$ less than 0.05 were considered as statistically significant.

\section{Results}

We determined PD-1.5 C/T gene polymorphism in 99 patients with CRC and 150 healthy controls. The study groups (patients and controls) had similar distributions of age, gender, family history, smoking and alcohol consumption. There was no notable age difference between the cases (62.06 \pm 12.8 years) and the controls (54.50 \pm 16.47 years). Characteristics of patients with CRC and controls regarding age, gender, and clinicopathological parameters (tumor location, tumor stage, lymph nodal metastasis, distance metastasis, angiolymphatic invasion, perineural invasion, the presence of mucinous component) are demonstrated in Table I. Table II shows the genotype and allele frequencies of PD-1.5 C/T polymorphism in CRC patients $(n=99)$ and controls $(n=150)$. The distributions of PD-1.5 C/T genotypes and alleles were in agreement with Hardy-Weinberg equilibrium in controls $(p>0.05)$ but not in CRC patients $(p=0.02)$. We found a statistically significant difference between CRC patients and controls for the genotypic distribution of PD-1.5 C/T genotypes $(p=0.003)$ and also for alleles $(p=0.004)$. The genotypic distributions of PD-1.5 C/T polymorphism comparing clinicopathological characteristics of patients with CRC are summarized and shown in Table III. There was found a higher frequency of CT genotype in CRC patients and this value was statistically significance $(p=0.016)$. The T allele frequency was higher in patients than controls $(p=0.001)$. There was a significant difference between the distant metastasis status and the distribution of PD-1.5 C/T genotypes ( $p=0.002)$. The patients who have distant metastasis have higher frequency of $C$ allele and CT genotypes than those with no metastasis $(p=0.016)$, The patients who have a mucinous component have higher frequency of the T allele than those with absence of the mucinous component $(p=0.023)$. Moreover, there was a significant difference between the presence of angiolymphatic invasion and PD-1.5 C/T genotypes $(p=0.023)$. The patients who have angiolymphatic invasion have higher frequency of the $C$ allele than those with absence of angiolymphatic invasion $(p=0.006)$. Another finding of our study is higher frequency of CC genotype in patients who have angiolymphatic invasion than those with no lymphatic invasion $(p=0.043)$.

\section{Discussion}

Preclinical and clinical studies recently focus on the modulation microenvironment that many researchers try to suggest new approches on some molecules which are involved in tumor-specific T-cell response in cancer. Therefore, a logical link can be established between polymorphisms of immune response-related genes that regulate $\mathrm{T}$ lymphocyte activation, and proliferation might contribute to cancer pathogenesis. The PD-1 molecule, a receptor of the CD28 family, is a well-characterized negative regulator of $T$ cells through its delivery of inhibitory signals [25]. Recent studies documented that PD-1 may be a candidate to 
become a biomarker gene for genetic susceptibilities of individuals to various types of cancer [33]. Accordingly, in the present study, we aimed to evaluate the possible association of PD-1.5 C/T polymorphisms with the clinical and pathological parameters of CRC. The prevalence of the heterozygous genotype of PD-1.5 C/T for our study was similar to the data reported by Li et al. in a Chinese population [25]. Furthermore, in another similar study on patients with non-small cell lung cancer (NSCLC), CT genotype frequency in healthy controls was reported as 31.8\% [34] and this was in accordance with Iranians, in whom it was 31\% [35]. In addition, $40 \%$ prevalence of the PD-1.5 C/T heterozygous genotype was reported in the Mexicans [36]. In the present report, the genotype distribution of PD-1.5 C/T was $42 \%$ CC, $46 \%$ CT, and $12 \%$ TT in controls, which was in accordance with the previous reports. At this locus, the $C$ allele had significantly higher prevalence among the controls than the patients. Haghshenas et al. reported low prevalence of TT genotype in the whole population for their study on thyroid cancer [37]. Similarly, we found lower prevalence of TT genotype in controls than patients.

The present study is one of the few studies investigating PD-1.5 C/T polymorphism and risk of CRC. According to our data, CT genotype in patients was more frequent than in control individuals. For the relation between CT genotype and CRC, our statistical analysis demonstrated a significant association, as did that of Mojtahedi et al. They suggested that CT genotype is probably a risk factor for this disease in Iranian patients [20]. Three meta-analyses have been conducted to evaluate the potential association between PD-1.5 $\mathrm{C} / \mathrm{T}$ polymorphism and the risk of cancer [38-40]. The results suggested that the T allele of PD-1.5 polymorphism significantly reduces cancer susceptibility. Also, Lin et al. indicated the association of the CT genotype and T allele with susceptibility to rheumatoid arthritis (RA). It was suggested that the $T$ allele might be associated with increased activity of T cells [41]. In the present study, the T allele for PD-1.5 C/T was more frequent in patients than controls, which was in accordance with the previous reports. This result was particularly due to the heterozygous $\mathrm{CT}$ genotype. According to that, our study supported the correlation of PD$1.5 \mathrm{C} / \mathrm{T}$ polymorphism with an increased possibility of developing CRC. However, $C$ allele frequency was more frequent in breast cancer patients than control individuals in the Chinese population [21]. Studies confirm that there is a large diversity in the PD1.5 genotype and allele frequency, depending on the variety of ethnic groups, tumor location, type of disease and other clinical factors.

According to our data, some clinical characteristics of the patients including age and gender
Table I. Characteristics of patients with CRC and controls

\begin{tabular}{|lcc|}
\hline Parameter & $\begin{array}{c}\text { Patients } \\
n(\%)\end{array}$ & $\begin{array}{c}\text { Controls } \\
n(\%)\end{array}$ \\
\hline No. of individuals & 99 & 150 \\
\hline Age, mean \pm SE [years] & $62.06 \pm 1.31$ & $54.50 \pm 4.4$ \\
\hline $\begin{array}{l}\text { Gender: } \\
\text { Male }\end{array}$ & $50(50.5)$ & $87(58)$ \\
\hline Female & $49(49.5)$ & $63(42)$ \\
\hline
\end{tabular}

Tumor location ${ }^{\mathrm{a}}$ :

\begin{tabular}{lcc}
\hline Left colon & $12(12.5)$ & - \\
\hline Right colon & $21(21.9)$ & - \\
\hline Transverse colon & $7(7.3)$ & - \\
\hline Sigmoid & $33(34.4)$ & - \\
\hline Caecum & $5(5.2)$ & - \\
\hline Rectum & $18(18.8)$ & - \\
\hline
\end{tabular}

Tumor stage:

\begin{tabular}{lcc}
\hline I & $3(3)$ & - \\
\hline II & $12(12.1)$ & - \\
\hline III & $52(52.5)$ & - \\
\hline IV & $32(32.3)$ & -
\end{tabular}

Lymph node status:

\begin{tabular}{lcc}
\hline N0 & $41(41.4)$ & - \\
\hline N1 & $35(35.4)$ & - \\
\hline N2 & $19(19.2)$ & - \\
\hline N3 & $4(4)$ & -
\end{tabular}

Distant metastasis:

\begin{tabular}{lll}
\hline Present & $37(37.4)$ & - \\
\hline Absent & $62(62.6)$ & -
\end{tabular}

\begin{tabular}{lll}
\hline Angiolymphatic invasion: & & \\
\hline Present & $18(18.2)$ & - \\
\hline Absent & $81(81.8)$ & - \\
\hline
\end{tabular}

Perineural invasion:

\begin{tabular}{lcc}
\hline Present & $34(34.39)$ & - \\
\hline Absent & $65(65.7)$ & -
\end{tabular}

Histological grade ${ }^{\mathrm{a}}$ :

\begin{tabular}{|lll|}
\hline Well differentiated & $22(26.5)$ & - \\
\hline Moderately differentiated & $38(45.8)$ & - \\
\hline Poorly differentiated & $23(27.7)$ & - \\
\hline Mucinous componenta: & & \\
\hline Positive & $27(38)$ & - \\
\hline Negative & $44(62)$ & - \\
\hline
\end{tabular}

$n$ - number of individuals, SD - standard deviation, SE - standard error. ${ }^{a}$ Data on tumor localization, histological grade and the presence of mucinous component were not available for all patients. 
Table II. Genotype and allele frequencies of PD-1.5 C/T polymorphism in CRC patients $(n=99)$ and controls $(n=$ 150)

\begin{tabular}{|c|c|c|c|}
\hline PD-1.5 C/T genotypes and alleles & $\begin{array}{c}\text { CRC patients } \\
n(\%)\end{array}$ & $\begin{array}{c}\text { Controls } \\
n(\%)\end{array}$ & $P$-value \\
\hline \multicolumn{3}{|l|}{ Genotype frequency: } & 0.003 \\
\hline CC (\%) & $21(21.2)$ & $63(42)$ & \\
\hline TT (\%) & $17(17.2)$ & $18(12)$ & \\
\hline $\mathrm{CT}(\%)$ & $61(61.6)$ & $69(46)$ & \\
\hline \multicolumn{3}{|l|}{ Allele frequency: } & 0.004 \\
\hline $\mathrm{C}(\%)$ & $103(52.0)$ & $195(65)$ & \\
\hline $\mathrm{T}(\%)$ & $95(48.0)$ & $105(35)$ & \\
\hline
\end{tabular}

$n$-number of participants, $p-p$-value, chi-square $\left(\chi^{2}\right)$ test is used between groups.

Table III. Distribution of PD-1.5 C/T genotypes, comparing clinicopathological parameters

\begin{tabular}{|c|c|c|c|}
\hline \multirow{2}{*}{ Parameter } & \multicolumn{3}{|c|}{ PD-1.5 } \\
\hline & $\begin{array}{c}\text { CC } \\
n(\%) \\
\end{array}$ & $\begin{array}{c}\mathrm{TT} \\
n(\%) \\
\end{array}$ & $\begin{array}{c}\mathrm{CT} \\
n(\%)\end{array}$ \\
\hline \multicolumn{4}{|l|}{ Gender: } \\
\hline Female & $11(22.4)$ & $6(12.2)$ & $32(65.3)$ \\
\hline Male & $10(20)$ & $11(22)$ & $29(58)$ \\
\hline \multicolumn{4}{|l|}{ Tumor stage: } \\
\hline III/IV & $15(17.9)$ & $15(17.9)$ & $54(64.3)$ \\
\hline I/II & $6(40)$ & $2(13.3)$ & $7(46.7)$ \\
\hline \multicolumn{4}{|l|}{ Lymph node status: } \\
\hline $\mathrm{N}+$ & $10(17.2)$ & $9(15.5)$ & $39(67.2)$ \\
\hline $\mathrm{N}-$ & $11(26.8)$ & $8(19.5)$ & $22(53.7)$ \\
\hline \multicolumn{4}{|l|}{ Metastasis: } \\
\hline Present & $4(10.8)$ & $2(5.4)$ & $31(83.8)$ \\
\hline Absent & $17(27.4)$ & $15(24.2)$ & $30(48.4)$ \\
\hline \multicolumn{4}{|l|}{ Angiolymphatic inv.: } \\
\hline Present & $7(38.9)$ & $5(27.8)$ & $6(33.3)$ \\
\hline Absent & $14(17.3)$ & $12(14.8)$ & $55(67.9)$ \\
\hline \multicolumn{4}{|l|}{ Perineural inv.: } \\
\hline Present & $8(23.5)$ & $4(11.8)$ & $22(64.7)$ \\
\hline Absent & $13(20)$ & $13(20)$ & $39(60)$ \\
\hline \multicolumn{4}{|l|}{ Histological grade: } \\
\hline Good to moderate differentiation & $13(21.7)$ & $10(16.7)$ & $37(61.7)$ \\
\hline Poor differentiation & $22(8.7)$ & $5(21.7)$ & $16(69.6)$ \\
\hline \multicolumn{4}{|l|}{ Mucinous component: } \\
\hline Positive & $1(3.7)$ & $7(25.9)$ & $19(70.4)$ \\
\hline Negative & $11(25)$ & $7(15.9)$ & $26(59.1)$ \\
\hline
\end{tabular}

$n$-number of patients, chi-square ( $\chi 2)$ test is used between groups, inv - invasion. 
were not associated with the PD-1.5 C/T polymorphism, which supports some studies that have investigated the importance of $1.5 \mathrm{C} / \mathrm{T}$ genotype distribution and allelic frequencies for cancer. In spite of that, the patients who have a late tumor stage have higher frequency of the $T$ allele than those with early stage tumor, although this difference was not statistically significant. However, we observed statistically significant associations between the PD1.5 C/T genotype frequencies and presence of distant metastasis, mucinous status, and angiolymphatic invasion. It is clearly observed that angiolymphatic invasion and angiogenesis are related to pathological features and other tumor characteristics, e.g. distant metastasis and lymph node metastasis are usually associated with poor prognosis [42]. In our study, carrying the $C$ allele and CT heterozygote genotype of PD-1.5 C/T polymorphism was more frequent in the patients who have distant metastasis than those with no metastasis. Moreover, the patients who have angiolymphatic invasion have higher frequency of the $C$ allele and CC genotype of PD-1.5 C/T polymorphism than those with absence of angiolymphatic invasion. Furthermore, the T allele was more frequent in patients who have a mucinous component than those with absence of a mucinous component.

In conclusion, our study, which is one of the few studies that have investigated of PD-1.5 C/T polymorphism and risk of CRC, suggested that PD-1.5 $\mathrm{C} / \mathrm{T}$ polymorphism may be associated with the risk and progression of colorectal cancer in our study group. The results of the study are consistent with the literature. Also our findings regarding the association of PD-1.5 C/T polymorphism and some pathological data, which are tumor grade, distant metastasis, mucinous status, and angiolymphatic invasion, should be extended to a larger sample size to clearly identify the effect of PD-1.5 C/T polymorphism on progression in CRC.

\section{Acknowledgments}

The present work was supported by a grant from the Ministry of Higher Education and Scientific Research through the Academic Mission, Libyan Embassy in Ankara, Turkey.

\section{Conflict of interest}

The authors declare no conflict of interest.

\section{References}

1. Jorgensen ML, Young JM, Solomon MJ. Optimal delivery of colorectal cancer follow-up care: improving patient outcomes. Patient Relat Outcome Meas 2015; 6: 12738.

2. Yin D, Morris CR, Bates JH, German RR. Effect of misclassified underlying cause of death on survival estimates of colon and rectal cancer. J Natl Cancer Inst 2011; 103 : 1130-3.

3. Gonzalez-Pons M, Cruz-Correa M. Colorectal cancer biomarkers: where are we now? Biomed Res Int 2015; 2015: 149014.

4. Singh PP, Sharma PK, Krishnan G, Lockhart AC. Immune checkpoints and immunotherapy for colorectal cancer. Gastroenterol Rep (Oxf) 2015; 3: 289-97.

5. Kocian P, Šedivcová M, Drgáč J, et al. Tumor-infiltrating lymphocytes and dendritic cells in human colorectal cancer: their relationship to KRAS mutational status and disease recurrence. Hum Immunol 2011; 72: 1022-8.

6. Charames GS, Bapat B. Genomic instability and cancer. Curr Mol Med 2003; 3: 589-96.

7. Mik M, Dziki L, Malinowska K, Trzcinski R, Majsterek I, Dziki A. Polymorphism of MSH2 Gly322Asp and MLH1 -93G >A in non-familial colon cancer - a case-controlled study. Arch Med Sci 2017; 13: 1295-302.

8. Coussens LM, Zitvogel L, Palucka AK. Neutralizing tumor-promoting chronic inflammation: a magic bullet? Science 2013; 339: 286-91.

9. Tesniere A, Apetoh L, Ghiringhelli F, et al. Immunogenic cancer cell death: a key-lock paradigm. Curr Opin Immunol 2008; 20: 504-11.

10. Nishimura H, Nose M, HiaiH, Minato N, Honjo T. Development of lupus-like autoimmune diseases by disruption of the PD-1 gene encoding an ITIM motif-carrying immunoreceptor. Immunity 1999; 11: 141-51.

11. Okazaki T, Honjo T. PD-1 and PD-1 ligands: from discovery to clinical application. Int Immunol 2007; 19: 813-24.

12. Thompson RH, Kuntz SM, Leibovich BC, et al. Tumor B7$\mathrm{H} 1$ is associated with poor prognosis in renal cell carcinoma patients with long-term follow-up. Cancer Res 2006; 66: 3381-5.

13. Erfani N, Razmkhah M, Talei AR, et al. Cytotoxic T lymphocyte antigen-4 promoter variants in breast cancer. Cancer Genet Cytogenet 2006; 165: 114-20.

14. Ohigashi Y, Sho M, Yamada Y, et al. Clinical significance of programmed death-1 ligand-1 and programmed death-1 ligand-2 expression in human esophageal cancer. Clin Cancer Res 2005; 11: 2947-53.

15. Finger LR, Pu J, Wasserman R, et al. The human PD-1 gene: complete cDNA, genomic organization, and developmentally regulated expression in B cell progenitors. Gene 1997; 197: 177-87.

16. Freeman GJ, Long AJ, Iwai Y, et al. Engagement of the PD-1 immunoinhibitory receptor by a novel B7 family member leads to negative regulation of lymphocyte activation. J Exp Med 2000; 192: 1027-34.

17. Latchman Y, Wood CR, Chernova T, et al. PD-L2 is a second ligand for PD-1 and inhibits T cell activation. Nat Immunol 2001; 2: 261-8.

18. Savabkar S, Azimzadeh P, Chaleshi V, et al. Programmed death-1 gene polymorphism (PD-1.5 C/T) is associated with gastric cancer. Gastroenterol Hepatol Bed Bench 2013; 6: 178-82.

19. Tang W, Chen Y, Chen S, et al. Programmed death-1 (PD-1) polymorphism is associated with gastric cardia adenocarcinoma. Int J Clin Exp Med 2015; 8: 8086-93.

20. Mojtahedi Z, Mohmedi M, Rahimifar S, Erfani N, Hosseini SV, Ghaderi A. Programmed death-1 gene polymorphism (PD-1.5 C/T) is associated with colon cancer. Gene 2012; 508: 229-32.

21. Hua Z, Li D, Xiang G, et al. PD-1 polymorphisms are associated with sporadic breast cancer in Chinese Han population of Northeast China. Breast Cancer Res Treat 2011; 129: 195-201. 
22. Haghshenas MR, Naeimi S, Talei A, et al. Program death 1 (PD1) haplotyping in patients with breast carcinoma. Mol Biol Rep 2011; 38: 4205-10.

23. Qiu, H, Zheng L, Tang W, Yin P, Cheng F, Wang L. Programmed death-1 (PD-1) polymorphisms in Chinese patients with esophageal cancer. Clin Biochem 2014; 47: 612-7.

24. Li Z, Li N, Zhu Q, et al. Genetic variations of PD1 and TIM3 are differentially and interactively associated with the development of cirrhosis and HCC in patients with chronic HBV infection. Infect Genet Evol 2013; 14 240-6.

25. Li XF, Jiang XQ, Zhang JW, Jia YJ. Association of the programmed cell death-1 PD1.5 C>T polymorphism with cervical cancer risk in a Chinese population. Genet Mol Res 2016; 15. DOI: 10.4238/gmr.15016357.

26. Zlobec I, Karamitopoulou E, Terracciano L, et al. TIA-1 cytotoxic granule-associated RNA binding protein improves the prognostic performance of CD8 in mismatch repair-proficient colorectal cancer. PLoS One 2010; 5: e14282.

27. Liang M, Fu J. Triptolide inhibits interferon-gamma-induced programmed death-1-ligand 1 surface expression in breast cancer cells. Cancer Lett 2008; 270: 337-41.

28. Kong EK, Prokunina-Olsson L, Wong WH, et al. A new haplotype of PDCD1 is associated with rheumatoid arthritis in Hong Kong Chinese. Arthritis Rheum 2005; 52: 1058-62.

29. Flores S, Beems M, Oyarzun A, Carrasco E, Perez F. Programmed cell death 1 (PDCD1) gene polymorphisms and type 1 diabetes in Chilean children. Rev Med Chi 2010; 138: 543-50.

30. Lee SH, Lee YA, Woo DH, et al. Association of the programmed cell death 1 (PDCD1) gene polymorphism with ankylosing spondylitis in the Korean population. Arthritis Res Ther 2006; 8: R163.

31. Cooper JD, Smyth DJ, Bailey R, et al. The candidate genes TAF5L, TCF7, PDCD1, IL6 and ICAM1 cannot be excluded from having effects in type 1 diabetes. BMC Med Genet 2007; 8: 71 .

32. Miller SA, Dykes DD, Polesky HF. A simple salting out procedure for extracting DNA from human nucleated cells. Nucleic Acids Res 1988; 16: 1215.

33. Li Y, Zhang HJ, Kang S, Zhou RM, Wang N. The effect of polymorphisms in PD-1 gene on the risk of epithelial ovarian cancer and patients' outcomes. Gynecol Oncol 2017; 144: 140-5.

34. Yin L, Guo H, Zhao L, et al. The programmed death-1 gene polymorphism (PD-1.5 C/T) is associated with non-small cell lung cancer risk in a Chinese Han population. Int J Clin Exp Med 2014; 7: 5832-6.

35. Namavar Jahromi F, Samadi M, Mojtahedi Z, Haghshenas MR, Taghipour M, Erfani N. Association of PD-1.5 $\mathrm{C} / \mathrm{T}$, but not PD-1.3 G/A, with malignant and benign brain tumors in Iranian patients. Immunol Invest 2017; 46: 469-80.

36. Zuniga J, Torres-García D, Jimenez L, et al. PDCD1 gene polymorphisms in different Mexican ethnic groups and their role in the susceptibility to hypersensitivity pneumonitis. Clin Biochem 2010; 43: 929-31.

37. Haghshenas MR, Dabbaghmanesh MH, Miri A, Ghaderi A, Erfani N. Association of PDCD1 gene markers with susceptibility to thyroid cancer. J Endocrinol Invest 2017; 40: 481-6.

38. Dong W, Gong M, Shi Z, Xiao J, Zhang J, Peng J. Programmed cell death-1 polymorphisms decrease the cancer risk: a meta-analysis involving twelve case-control studies. PLoS One 2016; 11: e0152448.

39. Tang $W$, Wang $Y$, Jiang $H$, et al. Programmed death-1 (PD-1) rs2227981C $>T$ polymorphism is associated with cancer susceptibility: a meta-analysis. Int J Clin Exp Med 2015; 8: 22278-85.

40. Mamat U, Arkinjan M. Association of programmed death-1 gene polymorphism rs2227981 with tumor: evidence from a meta analysis. Int J Clin Exp Med 2015; 8: 13282-8.

41. Lin SC, Yen JH, Tsai JJ, et al. Association of a programmed death 1 gene polymorphism with the development of rheumatoid arthritis, but not systemic lupus erythematosus. Arthritis Rheum 2004; 50: 770-5.

42. Mohammed ZM, McMillan DC, Edwards J, et al. The relationship between lymphovascular invasion and angiogenesis, hormone receptors, cell proliferation and survival in patients with primary operable invasive ductal breast cancer. BMC Clin Pathol 2013; 13: 31. 